\title{
The Effect of the Temperature of Plain or Sweetened Water on Body Composition in Rats
}

\author{
Carla El-Mallah ${ }^{\mathrm{a}}$ Marie-Elizabeth Ragi ${ }^{\mathrm{b}} \quad$ Nehmat El-Helou $^{\mathrm{b}}$ Omar Obeid $^{\mathrm{b}}$ \\ ${ }^{a}$ Faculty of Medicine, American University of Beirut, Beirut, Lebanon; ${ }^{b}$ Department of Nutrition and Food Sciences, \\ American University of Beirut, Beirut, Lebanon
}

\section{Keywords}

Water · Temperature · Sweeteners · Weight · Body composition

\begin{abstract}
Introduction: Humans are known to adapt to external temperature variations by altering energy intake, expenditure, and body fat storage for insulation [1, 2]. However, it is not clear whether the temperature of ingested water would induce such effects. Similarly, the involvement of the temperature of the ingested beverage has not been addressed in terms of body weight changes [3]. Objectives: This study was to investigate the effect of the ingestion of plain or sweetened water with varied temperatures on growth measures of rats. Methods: Approval was obtained from the Institutional Animal Care and Use Committee of the American University of Beirut. After a 1-week adaptation period, 5- to 6-week-old male Sprague-Dawley rats were randomly divided into their respective experimental groups, housed individually $\left(22 \pm 1^{\circ} \mathrm{C}\right.$, reverse light cycle $12: 12 \mathrm{~h}$ dark/light, light off at 10:00 a.m.) with free access to food and beverage for 8 weeks. Experiment 1 (Plain Water): Two groups of rats ( $n=$ 9) consumed room-temperature $\left[\sim 22^{\circ} \mathrm{C}\right](\mathrm{NW})$ or cold $\left[\sim 5^{\circ} \mathrm{C}\right]$ (CW) water. Experiment 2 (Sweetened Water): Four groups of rats were offered sweetened water for $12 \mathrm{~h}$, followed by
\end{abstract}

plain water; (1) $10 \%$ sucrose + cold temperature (CS, $n=7)$, (2) $10 \%$ sucrose + room temperature (NS, $n=8$ ), (3) $0.05 \%$ acesulfame $\mathrm{K}+$ cold temperature (CA, $n=7$ ), and 4$) 0.05 \%$ acesulfame $\mathrm{K}$ + room temperature (NA, $n=8)$. Food and beverage intake, body weight, and body composition were monitored using NMR minispec (LF110 Body Composition Analyzer, Bruker, USA) and energy expenditure was calculated based on the equation developed by Ravussin et al. [4]. Significance was set at a $p$ value $<0.05$. Results: Experiment 1: Body weight changes were similar between groups (Fig. 1-Exp 1a). In the CW group, lean body mass (\%) was significantly higher, while body fat (\%) was lower than the NW (Fig. 1-Exp 1b, c). These changes may relate to the calculated total energy expenditure [NW: $66.73 \pm 4.49 \mathrm{kcal} /$ day and $\mathrm{CW}$ : $73.75 \pm 3.92 \mathrm{kcal} /$ day) ( $p$ value $=0.003$ ) since energy intake (NW: $89.97 \pm 7.63 \mathrm{kcal} /$ day vs. CW: $93.29 \pm 6.26 \mathrm{kcal} /$ day, $p$ value $=0.329)$ was similar between groups. Experiment 2 : Body weight of the CA group was higher than that of the other groups (Fig. 1-Exp 2a). Lean body mass (\%) of the sucrose-sweetened water groups (Fig. 1-Exp 2b, c) was significantly higher, while body fat (\%) was lower than that of the non-caloric sweetened water groups; these were not affected by the temperature of the beverage. Those variations are mostly explained by the differences in energy expenditure ( $p$ value temperature $\times$ sweetener $=0.015$ ), as energy intake was not significantly different between groups. Conclusion: karger@karger.com www.karger.com/anm

Karger $\frac{1}{\%}$
(C) 2021 The Author(s)

Published by S. Karger AG, Basel

This article is licensed under the Creative Commons AttributionNonCommercial-NoDerivatives 4.0 International License (CC BYNC-ND) (http://www.karger.com/Services/OpenAccessLicense). Usage and distribution for commercial purposes as well as any distribution of modified material requires written permission.
Correspondence to:

Omar Obeid,oo01@aub.edu.lb 


\section{Experiment 1: Plain water}
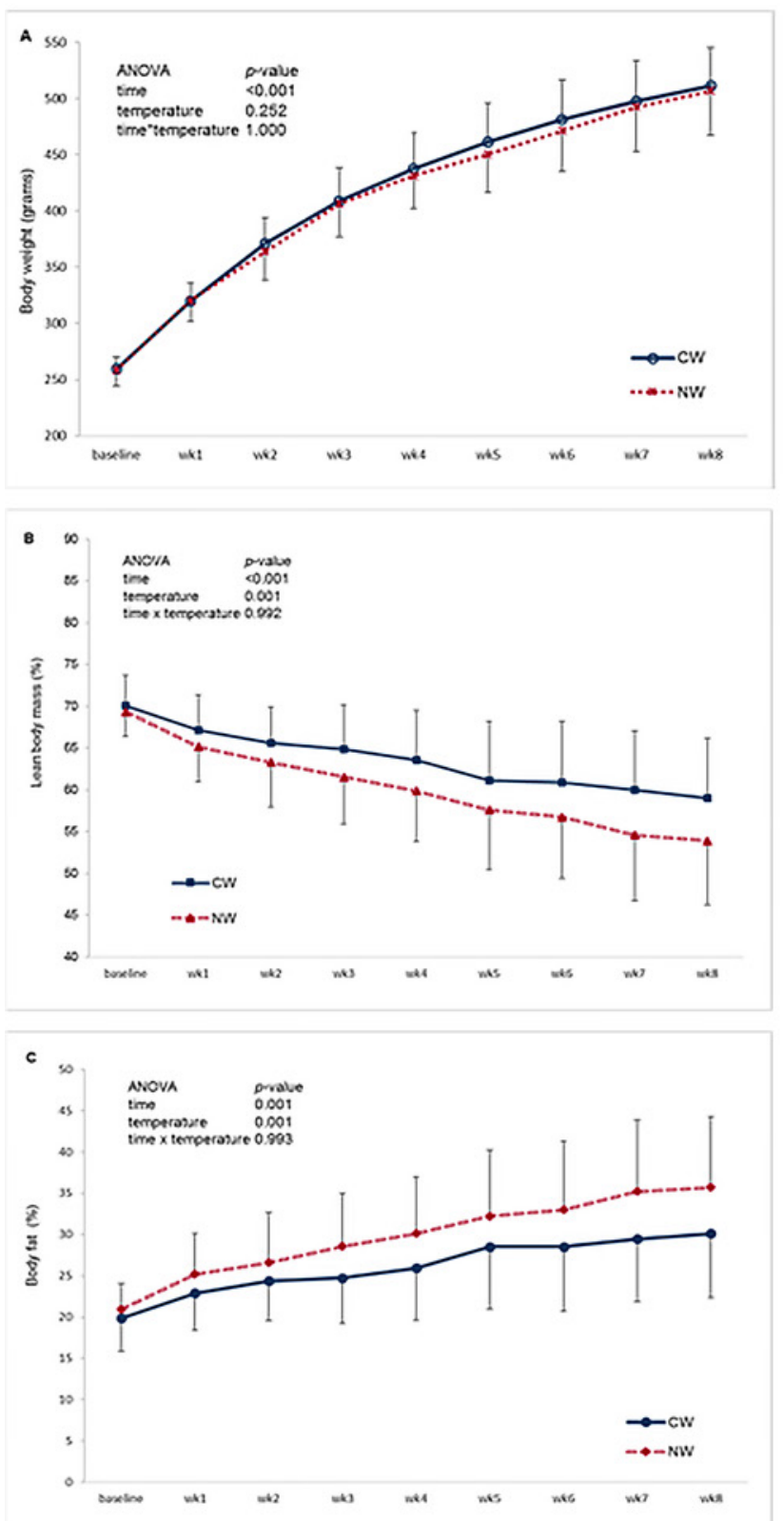

Experiment 2: Sweetened water
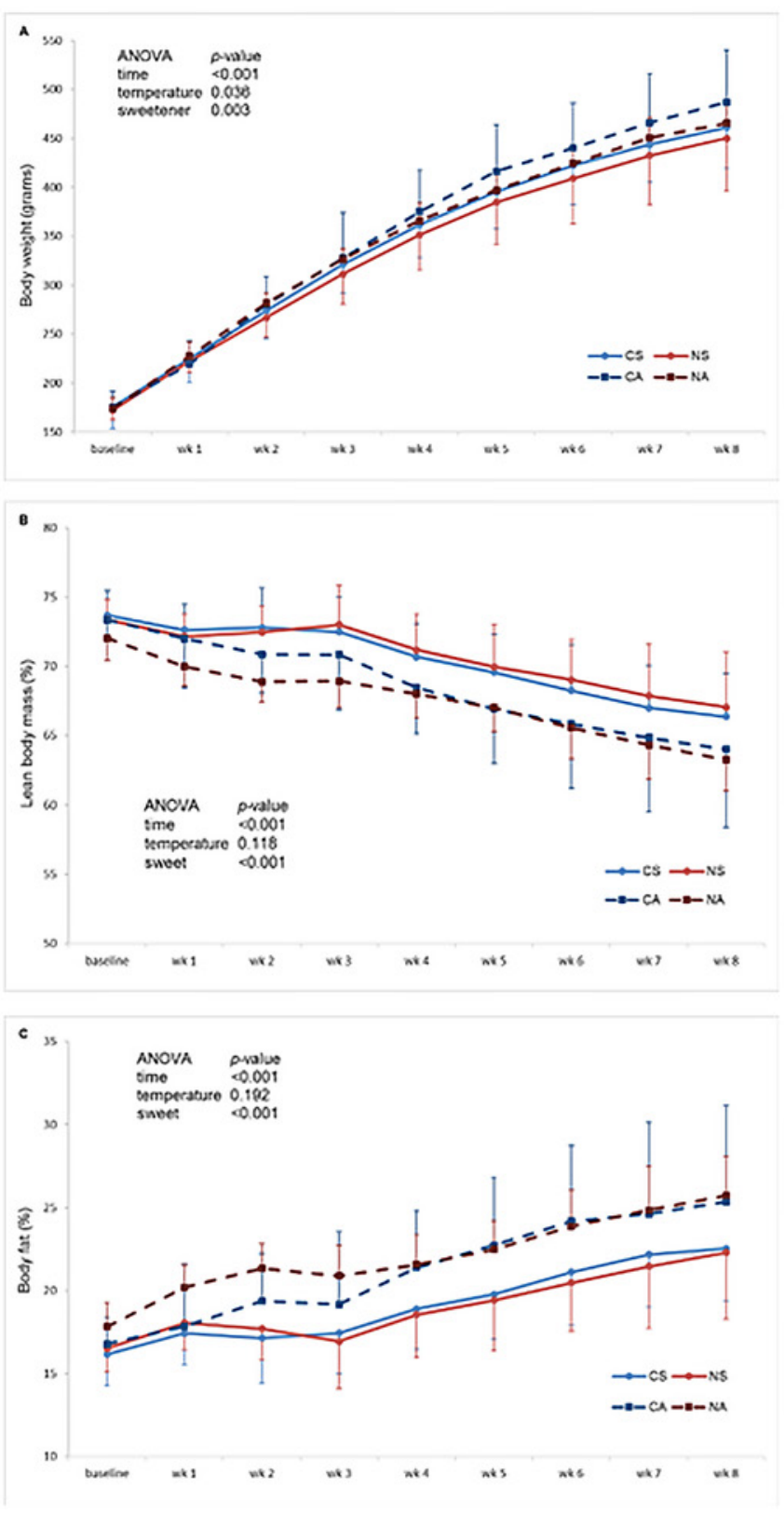

Fig. 1. Body weight (g), lean body mass (\%), and body fat (\%) of the rats over 8 weeks. Experiment 1 - weekly body weight (a), lean body mass (b) and body fat (c) gain of group CW: cold water (about $4^{\circ} \mathrm{C}$ ); group NW: room-temperature water (about $22^{\circ} \mathrm{C}$ ). Blue lines refer to CW; red lines refer to NW. A two-way ANOVA was performed with time and temperature of the water as factors, and time set as random. Experiment 2 - weekly body weight (a), lean body mass (b) and body fat (c) gain from baseline in grams of group CS: cold water (about $4^{\circ} \mathrm{C}$ ) sweetened with $10 \%$ sucrose; group NS: room-temperature water (about $22^{\circ} \mathrm{C}$ ) sweetened with $10 \%$ sucrose; group CA: cold water (about $4^{\circ} \mathrm{C}$ ) sweetened with $0.05 \%$ acesulfame K; group NA: room-temperature water (about $22^{\circ} \mathrm{C}$ ) sweetened with $0.05 \%$ acesulfame K. A multiple-way ANOVA was performed with time set as random, temperature of beverages and type of sweeteners as factors. All data are expressed as mean values and standard deviations of all values. Significance was set at $p<0.05$. CW, cold water; NW, normal temperature water. 
Cold plain water decreased body fat and increased lean body mass with no effect on total body weight. Sucrose-sweetened water had a better impact on body composition irrespective of the temperature of the beverage. The beneficial effects are mainly due to increased energy expenditure rather than variations in energy intake. Thus, the energy cost of warming the water seems to have been derived from an increase in fat oxidation.

(C) 2021 The Author(s)

Published by S. Karger AG, Basel

\section{Conflict of Interest Statement}

C.E.M. received travel expenses and registration fees from $\mathrm{Da}$ none Research to attend the 2019 Hydration for Health Scientific Conference. The other authors declare no conflict of interest.

\section{Funding Sources}

American University of Beirut funds. Collaborative Research Stimulus. Award no 103559. Project no. 24470. The funder had no role in study design, data collection, and analysis, decision to publish, or preparation of the manuscript.

\section{Author Contributions}

O.O. conceived and designed the experiment; C.E.M., M.E.R., and N.E.H. carried out the experiments and conducted the laboratory analysis. All authors analyzed the data and were involved in the write up of the paper and had final approval of the submission.

\section{References}

1 van Marken Lichtenbelt WD, Schrauwen P, van de Kerckhove S, Westerterp-Plantenga MS. Individual variation in body temperature and energy expenditure in response to mild cold. Am J Physiol Endocrinol Metab. 2002 May 1;282(5):E1077-83.

2 Dauncey MJ. Influence of mild cold on $24 \mathrm{~h}$ energy expenditure, resting metabolism and diet-induced thermogenesis. Br J Nutr. 1981 Mar;45(2):257-67.
3 Fowler SP, Williams K, Resendez RG, Hunt KJ, Hazuda HP, Stern MP. Fueling the obesity epidemic? Artificially sweetened beverage use and long-term weight gain. Obesity. 2008 Aug;16(8):1894-900.

4 Ravussin Y, Gutman R, LeDuc CA, Leibel RL Estimating energy expenditure in mice using an energy balance technique. Int J Obes. 2013 Mar;37(3):399. 